\title{
Are Emerging Markets Resilient to Global Financial Shocks? Evidence from Developing Country Banking Sector
}

\author{
Asim Rehman
}

\begin{abstract}
Adverse effects of vulnerability in the financial sector have been seen, yet again, during the financial crisis of 2008 that turned into a domino effect on the international financial markets spreading across the developed world. The misfortune seen by the developed countries spread its wings into all corners of the world, but there seems to be a misunderstanding of the threat arising of such an event in the regulators of some developing countries. Pakistan is one such country. The regime at the time maintained that the country had been insulated from the adverse effects of the crisis on the financial sector. More emphasis was placed on the macroeconomic imbalances due to global rise in commodity and oil prices. The present study aims to show whether or not the financial crisis impacted the performance efficiency of the Pakistani banking sector and whether the effects were short lived or prolonged. This has been achieved using a unique variable selection methodology in data envelopment analysis using the Malmquist index approach which, to the author's best knowledge, has never been used for the purpose of a similar analysis. The results prove that the performance efficiency of the banking sector was indeed effected during the crisis years but were restored to pre-crisis levels soon after. This goes to show that even though the regulators were partially correct in terms of the timeframe effects of the crisis, yet there was a strong impact on the efficiencies that proves that financial sector was indeed impacted and also, if left unchecked, can have dire consequences if any such situation does arise in the future. The conclusion of the study suggests further work needs to be done on the channels of transmission of the crisis on Pakistan.
\end{abstract}

Index Terms-Data envelopment analysis, emerging markets, financial crisis, performance efficiency.

\section{INTRODUCTION AND BACKGROUND OF STUDY}

The financial sector plays a vital role in the smooth functioning of an economy. There have been various studies that talk about the impact of the financial industry on economic growth while others consider them to be of utmost importance saying that any inefficiencies in this sector can lead to a systemic crisis and have dire effects on the whole economy [1]. Therefore, the importance of bank performance has been a vital area of interest to various stakeholders including the customers, regulators, capital providers and depositors.

Manuscript received August 7, 2016; revised December 15, 2016.

Rehman is with the National University of Science and Technology, Islamabad, Pakistan (e-mail: asim.rehman @ nbs.nust.edu.pk).
Performance efficiency of banks has been a recent topic of interest in the finance literature [2]. Most of the previous research is based around the traditional financial ratios including ROA (Return of assets), ROE (Return of equity). Though using these has become a norm in performance measurement studies using data envelopment analysis (DEA), there is rarely a presentation or reference made to the reason for the selecting the said variables or empirical justification, even though use of the right combination of input and output variables lies at the core of the analysis. Interestingly, not many papers seem to have been concerned about this basic aspect in their analysis. Hiroshi Morita and Necmi K. Avkiran [3] in their 2009 study fill this gap by using diagonal layout experiments, which is a statistical approach, to find the optimal input output combinations for the purposes of performance efficiency analysis of financial firms using DEA. This study uses the results of their analysis as the variable selection methodology making it unique in literature. We use it to study the performance efficiency of the Pakistani banking sector during the recent global financial crisis. Before talking about the previous studies performed on the topic we first take a look at the evolution of the Pakistani banking sector over the past few decades.

The role of the banking sector in Pakistan has seen increased importance. Since the nationalization of the banking sector in 1974, when there was dominance of government owned banks even though there was minor presence of foreign banks in the sector. During the 1990's, at the recommendation of the World Bank and IMF, the government of Pakistan undertook a massive reforms agenda for the entire financial sector. The agenda revolved around restructuring current financial institutions, improving supervision standards, increasing competition by licensing new private banks. This led to the government privatizing two of the largest commercial banks in the country, namely MCB (Muslim Commercial Bank) and ABL (Allied Bank of Pakistan).

The next phase of privatization came at the turn of the century when then regime decided that more needs to be done to better utilize the potential of the financial sector in the country. This phase involved privatizing of more major government owned banks including United Bank Limited and Habib Bank Limited which are amongst the top 5 banks in the country. Another major change that took place was the licensing of various new commercial banks as well as entry of foreign banks in the country. This included names like RBS (Royal Bank of Scotland) and SCB (Standard Chartered Bank).

Seeing as the Pakistani banking sector was flourishing in 
the few years preceding the financial crisis, any changes to that trend would be a clear indication of a shock to the system. When it started to affect the financial sector, the crisis showed the vulnerability of the global financial system to unexpected shocks and led to increased supervision and regulatory reforms, such as the introduction of the liquidity coverage ratio LCR and the Net Stable Funding Ratio NSFR. The crisis impacted many parts of the developing world which were not the originators of nor directly connected to the crisis originating countries.

There are many techniques of checking the performance efficiency or impact of the crisis on Pakistan, these spread from both parametric to non-parametric approaches. Many studies have used a non-parametric approach for the evaluation of banking sector inefficiencies. The most popular method for doing so is by the use of data envelopment analysis. Data envelopment analysis, also known as frontier analysis, was developed in 1978 by Cooper, Charnes and Rhodes. Data envelopment analysis (or DEA) is a technique used for performance measurement and evaluation of relative efficiencies of decision making units (or DMU's). DMU's are distinct units which within an organization or an economy which have the flexibility when it comes to making some decisions, but they are bound by certain constraints with regards to those decisions.

We are using the DEA approach using Malmquist index and a unique variable selection methodology first time being used in literature, as per the author's knowledge, for checking the performance efficiency of the Pakistani banking sector. There have been previous studies on the effects of the financial crisis on both international and Pakistani markets. These studies have used several different statistical methodologies to arrive at their results. Discussed below are various studies that use both parametric and non-parametric approaches in their work. We discuss both studies to show some of the results obtained by previous researchers as well as to establish a theoretical framework of the topic and our study. To insert images in Word, position the cursor at the insertion point and either use Insert | Picture | From File or copy the image to the Windows clipboard and then Edit | Paste Special | Picture (with "Float over text" unchecked).

\section{LITERATURE REVIEW}

The global financial crisis of 2008 led to many problems in the worldwide banking system. Weak asset classes exposed the banks to liquidity shortages and ultimately had to be rescued. The impact of the crisis on the developing world has been studied. Studies have been conducted on the Pakistani economy and banking sector that talk about the macroeconomic impact of the crisis on Pakistani economy including the impact on government spending, GDP, trade, employment and poverty by [4]. Their results indicated that as a result of the crisis there was a decrease in government spending, decline in real GDP, increase in unemployment and increase in poverty levels. They used CGE-microsimulation model showing how a reduction in foreign remittances had negative impact on the GDP, inequality and poverty in the country.

Furthermore [5], talk about the impact of exchange rates, oil prices and interest rate on the Pakistani economy in context of financial crisis of 2008. Their study employed a multivariate regression model, and ANOVA was used to test the significance of the equation. Their results indicated that exchange rates, oil prices and interest rate do have an impact on the financial crisis. Both these studies show that the Pakistani sector was indeed affected by the crisis, while these studies focused on the economic indicators we further look at the strand of literature focusing on the financial sector performance during the crisis.

Ref. [6], looked at the performance of the Pakistani financial sector during the crisis by looking at the determinants of financial performance using a stepwise multiple regression analysis post and pre crisis. Their results indicated that the financial crisis had significantly impacted the effects that various indicators had on measuring the financial performance. For example the investments had more role in positive financial performance post crisis then pre crisis while advances were more helpful in pre-crisis years then in post. Their results are intuitive as they prove that liquidity shortages affected the credit worthiness of the clients and an increase in the non-performing loans. As opposed to these the quality of investments made by the financial institutions became more important in the determination of performance.

Ref. [7], did a comparison between the performance of Islamic and conventional commercial banks during the financial crisis in Pakistan. To do this they performed a comparative analysis on the major financial ratios of five Islamic and five commercial banks from 2008 to 2009. Their results indicated that the performance of the Islamic banks surpassed that of the conventional banks during the period. They attributed this to the fact that Islamic banks are prohibited from undertaking activities like investing in toxic assets and prohibition of Riba. So far it is clear that there was indeed effect of the crisis on Pakistan's real economy as well as on the financial sector. We further look at the works related to non-parametric approaches to performance efficiency of the banking sector.

There are previous studies that have employed non-parametric techniques for performance efficiency calculation. [8] Worked on the South African banking sector. They used cost based DEA in combination with ratio analysis using profitability and market value ratios to determine their impact of performance efficiency. They concluded that market value ratios are impacted by any changes in profitability ratios and hence profitability ratios should be used as a proxy for market ratios rather than separate measures.

Ref. [9] studied the performance efficiency of the Pakistani banking sector using DEA methodology. Contrary to our study, their work focused on the various types of banks classified as state-owned banks, domestic private banks and foreign owned banks. Their time period is also separate from current study and looks at the performance from 2001-2008 and does not account for the impact of the financial crisis on the efficiency of the banks. They concluded that scale inefficiency is the main source of overall technical inefficiency.

Ref. [10] has also worked on the Pakistani banking sector 
using DEA. They employ the intermediation approach as they were using both Islamic and conventional banks in the analysis as Islamic banks have an equity based capital structure. They also use standard measures of input and output selection. Their results show that the performance of Islamic banks was better than the conventional banks during the period of the study which is from 2006 up until 2010.

Ref. [11] worked on the performance efficiency of commercial banks in Nigeria using DEA using not only constant returns to scale (CRS) and variable returns to scale (VRS) approaches, but also scale efficiency models. They also use standardized input output combinations in their study that are not based on any statistical measures for optimal input output variable selection. Their results indicated that small and medium banks performed better than the bigger banks during the period of the study which is 2009. All the performance measurement studies about performance measurement above have used the standard approaches for the purposes of variable selection. We will now look at the studies that have used advanced statistical tools to arrive at the input-output combinations for DEA.

There are previous studies that look at input output combination for a financial firm using DEA analysis. [12] used a genetic algorithm to come up with the variables and then using the method purposed by [13] they arrived at the final set of input output combination by running DEA on the subgroup arrived at using the genetic algorithm. They estimated 35 models for DEA and then came up with the best model using the $10 \%$ change in efficiency scores of the banks.

Variables selected for use in the Data Envelopment Analysis for our study come from the work of [3], who have used an input output selection method based on discriminant analysis using external evaluation and a three level orthogonal layout experiment, calculating the Mahalanobis distance and checking with ANOVA. Their six step selection method leads to the following variables as the optimum ones. Input: Debt Ratio; Output: Market Price, Total Assets, Gross Profit and Net profit. These are the variables that are being employed in this study to perform the analysis of DEA.

This study is unique as to the author's best knowledge there is no previous study that uses the optimal input-output combination given by [3] to study the efficiency of the banking sector. This adds value to the results of this study as they are not based on intuitive selection but estimate efficiency based on variables selected using advanced statistical methods.

\section{HYPOTHESIS FORMULATION}

Based on the previous studies, few of which have been mentioned in the section above, it is seen that the economic situation of Pakistan worsened after the 2008 financial crisis, considering this, the first hypothesis of this study is that:

H1: The financial crisis impacted technical, technological and pure efficiencies of the banking sector in Pakistan

The reason for the above hypothesis is because these measures of performance are exposed to changes in the short term due to any shock in the system and as soon as the shock is absorbed they are expected to go back to normal.

Since Pakistan is not a crisis originating country and the impact is due to spillover from the international markets so it is expected that the scale efficiency component, which measure the efficiency due to size of the banking sector, will not be impacted leading to the second hypothesis:

\section{H2: The financial crisis did not impact the scale efficiency of the Pakistani banking sector}

In terms of the total factor productivity, which measures how intensely and efficiently the inputs are used in production, would be impacted during the crisis years, but would be short living and go back pre-crisis levels afterwards. So the third hypothesis of the study is:

H3: Total factor productivity of the Pakistani banking sector is affected due to the global financial crisis but the effects would be short lived

The hypothesis will be tested in the following sections using the data envelopment analysis approach to performance measurement, specifically using the Malmquist index approach.

\section{Methodology And DatA}

Data has been gathered from 2006 to 2010 for 20 banks in the Pakistani banking sector. These include banks from the public sector, private sector including commercial banks and Islamic banks. The variables that are collected are based on the paper by [3]. The optimal combination of input and output for any financial sector firm according to the study is:

Input:

- Debt Ratio, which is defined the total liabilities divided by the total assets

Output:

- Total assets, the total assets that the bank has.

- Ordinary profit, which is the income from the regular operations of the bank (from operating activities).

- Net profit, the net profit made by the bank after adjusting for the expenses after the gross profit.

- Market price of firm, defined as the total number of shares outstanding into the market price per share, the market price is taken as the average for each year being studied.

Collection for the required data has been done from the State Bank of Pakistan issued reports and website of Karachi stock exchange of Pakistan. The data has been transferred from the reports and webpage onto Microsoft Excel spreadsheets where it has been treated to make it viable for data envelope analysis. The software used to perform the DEA analysis is Data Envelope Analysis (Computer) Program Version 2.1. For using the software the data was transferred from the spreadsheet into a txt file and then the analysis was done.

In most cases when DEA is performed it is done so for a specific time period. But when there is need to check 
efficiency across various time periods, the changes in total factor productivity needs to be checked for which panel data is required. The panel needs to be balanced in order for the analysis to be performed. Various indexes are used to measure the changes in total factor productivity; these are calculated as ratios of output indexes to input indexes. Indexes are defined as real numbers used to show the degree change in a set of related variables. They can be used to compare changes in variables thorough time, place or both.

Malmquist index measures the DMU's (which are the decision making units i.e. firms under study or in this case banks) changes in total factor productivity by time. More specifically, the Malmquist index for total factor productivity (TFP) measures the change in TFP amongst two data points by finding out the ratio of the distances of each data point in relation to a common technology. This is measured using the distance function which is able to define the production technologies for multiple inputs and outputs regardless of cost minimization or profit maximization objectives [14]. The input function is able to define the production technology based on the most contracted input vector where the output vector is given. Similarly, output distance function defines the production technology as per the maximum expanded input vector where it is given [15]. The name of the index is based on the name of Sten Malmquist, who gave the idea of calculating indexes with the help of distance functions.

This research aims to check the performance efficiency of Pakistani banking sector by using input-output combination based on work of [3] who use discriminant analysis by external evaluation and three level orthogonal layout experiments calculating the Mahalanobis distances to arrive at the optimal variable selection. These variables are then used for calculating the generalized output-oriented Malmquist index, which is based on the works of [16], using non-parametric approach of Data Envelopment Analysis (DEA) using software called DEAP 2.1 developed by [17]. [16] were the first to show how Malmquist productivity index, output based, amid two time period $\mathrm{t}$ and $(\mathrm{t}+1)$ may be segregated to 2 parts, given below:

$$
M_{K}^{t+1}\left(y^{t+1}, x^{t+1}, y^{t}, x^{t}\right)=\left[\frac{\mathrm{D}_{\mathrm{k}}^{t}\left(y^{t+1}, x^{t+1}\right)}{\mathrm{D}_{\mathrm{k}}^{t}\left(y^{t}, x^{t}\right)} \times \frac{\mathrm{D}_{\mathrm{k}}^{t+1}\left(y^{t+1}, x^{t+1}\right)}{\mathrm{D}_{\mathrm{k}}^{t+1}\left(y^{t}, x^{t}\right)}\right]^{\frac{1}{2}}
$$

In (1) above, $M$ represents the most recent production point's $\left(\mathrm{x}^{\mathrm{t}+1}, \mathrm{y}^{\mathrm{t}+1}\right)$ productivity relative to the earlier production point $\left(\mathrm{x}^{\mathrm{t}}, \mathrm{y}^{\mathrm{t}}\right)$ of bank $k$. Where $D$ 's are distance functions for outputs. As per [16], the alternative way of expressing (1) above is:

$$
M_{k}^{t+1}\left(y^{t+1}, x^{t+1}, y^{t}, x^{t}\right)=\frac{\mathrm{D}_{k}^{t+1}\left(y^{t+1}, x^{t+1}\right)}{\mathrm{D}_{k}^{t}\left(y^{t}, x^{t}\right)} \times\left[\frac{\mathrm{D}_{k}^{t}\left(y^{t+1}, x^{t+1}\right)}{\mathrm{D}_{k}^{t+1}\left(y^{t+1}, x^{t+1}\right)} \times \frac{\mathrm{D}_{k}^{t}\left(y^{t}, x^{t}\right)}{\mathrm{D}_{k}^{t+1}\left(y^{t}, x^{t}\right)}\right]^{\frac{1}{2}}
$$

\section{or, $\mathrm{M}=\mathrm{EFFCH} \times \mathrm{TECHCH}$ where,}

$$
\text { Technical Efficiency Change }(E F F C H)=\frac{\mathrm{D}_{k}^{t+1}\left(y^{t+1}, x^{t+1}\right)}{\mathrm{D}_{k}^{t}\left(y^{t}, x^{t}\right)}
$$

and,

Technological Efficiency Change $(T E C H C H)=\left[\frac{\mathrm{D}_{k}^{t}\left(y^{t+1}, x^{t+1}\right)}{\mathrm{D}_{k}^{t+1}\left(y^{t+1}, x^{t+1}\right)} \times \frac{\mathrm{D}_{k}^{t}\left(y^{t}, x^{t}\right)}{\mathrm{D}_{k}^{t+1}\left(y^{t}, x^{t}\right)}\right]^{\frac{1}{2}}$
First considers how adequately inputs are converted to output in the production process while the later represents technological improvements. As per [18] performance improvement is due to having a value above one for the Malmquist index over a certain time period, while decrease is related to a Malmquist index lesser then one. Similarly, technical efficiency change value above unity shows that the efficiency part has improved and values of the efficiency related to change in technology component greater than unity show improvement in technology.

Now, assuming $k=1,2,3, \ldots, K$ banks then at every changing quantities of $n=1,2,3, . ., N$ changed inputs $x_{k, n}^{t}$ to produce $m=1,2,3, \ldots, M$ outputs $y^{t} k$ on every period $t=1,2$, $3, \ldots, T$. Hence, CRS (constant returns to scale) technology at every period $t$ from the data is given by:

$$
\begin{aligned}
& G^{t}=\left\lfloor\left(x^{t}, y^{t}\right): y_{m}^{t} \leq \sum_{k=1}^{K} z_{k}^{t} y_{k, m}^{t}\right\rfloor m=1 \ldots \ldots . M \\
& \sum_{k=1}^{K} z_{k}^{t} y_{k, m}^{t} \leq x_{n}^{t} \quad n=1 \ldots \ldots . . N \\
& z_{k}^{t} \geq 0 \quad k=1 \ldots \ldots . . K
\end{aligned}
$$

Here, $z^{t} k$ shows the weight on every precise cross-sectional observation. According to Afriat (1972), the CRS assumption could be removed allowing variable returns assumption (VRS) by incorporating constraints as follows:

$$
\sum_{k=1}^{K} z_{k}^{t}=1 \ldots \ldots(V R S)
$$

Ref. [18] decomposed the Malmquist index's efficiency change component considered relatively to constant returns to scale technology to pure efficiency component (in relation to variable returns to scale technology) also component about scale efficiency change capturing deviation amid CRS and VRS technology. Separating the pure efficiency change allows measuring the comparative ability of units to change inputs into outputs whereas scale efficiency measures the extent that units may yield benefit of returns to scale by changing magnitude near the optimum level.

Therefore,

Technical Efficiency Change $(\mathrm{EFFCH})=\mathrm{PECH} \times \mathrm{SECH}$ where,

Pure Technical Efficiency Change $(P E C H)=\frac{\mathrm{D}_{\mathrm{v}}^{t+1}\left(x_{k}^{t+1}, y_{k}^{t+1}\right)}{\mathrm{D}_{\mathrm{v}}^{t}\left(x_{k}^{t}, y_{k}^{t}\right)}$ and,

Scale Efficiency Change $(S E C H)=\frac{\mathrm{D}_{\mathrm{c}}^{t+1}\left(x_{k}^{t+1}, y_{k}^{t+1}\right) / \mathrm{D}_{v}^{t+1}\left(x_{k}^{t+1}, y_{k}^{t+1}\right)}{\mathrm{D}_{\mathrm{c}}^{t}\left(x_{k}^{t}, y_{k}^{t}\right) / \mathrm{D}_{\mathrm{v}}^{t}\left(x_{k}^{t}, y_{k}^{t}\right)}$

In above subscript 'c' and ' $\mathrm{v}$ ' denotes CRS and VRS technologies, respectively. $\mathrm{PECH}$ values above one indicate an increase in pure technical efficiency, while below one indicate a decline and equal to one indicates that there is no change. Similarly, SECH above one show that the most efficient scale is growing overtime; hence there is improvement in the scale efficiency, whereas SECH below one suggests the contrary while value of one suggests there 
has not been a change.

If index formulation of Malmquist is for adjacent time periods, calculation shall be made for various distance functions $-D^{t}\left(y^{t}, x^{t}\right), D^{t}\left(y^{t+1}, x^{t+1}\right), D^{t+1}\left(y^{t}, x^{t}\right), D^{t+1}\left(y^{t+1}\right.$, $x^{t+1}$ ), four in total. Using DEAP v. 2.1 made by [17] and [18] approach, five efficiency indices for each firm are provided along with a degree of progress (technical) over time. These are:

(i) Technical Efficiency Change (EFFCH)

(ii) Technological Efficiency Change (TECHCH)

(iii) Pure Technical Efficiency Change (PECH)

(iv) Scale Efficiency Change (SECH)

(v) Total Factor Productivity Change (TFPCH)

In the following section we will be looking at the results obtained using the above mentioned methodology and take a in depth look at the meaning of those findings in the discussion.

\section{EMPIRICAL RESULTS AND DISCUSSION}

The results for the analysis are given in Table I to 6 below along with detailed discussion of the findings. The descriptive table below shows that the mean size of the DMU's stands at around Rs. 230 million with a wide gap between the minimum and maximum values of 4 million and 944 million, with a standard deviation of about 230 million. The ordinary profits have a mean of 3.9 million with a standard deviation of about 28 million. The net profit follows a similar pattern with mean value of 2.8 million and a standard deviation of about 6 million. The mean market value of the DMU stands at 35.7 million with a standard deviation of 51 million. The mean debt to asset ratio is 0.89 with a standard deviation of 0.08 .

Table II shows the technical efficiency scores for the years under study for all the DMU's. The results show that the technical efficiency of the banks was impacted during 2009 with the mean scores falling to 0.882 for the year. The scores recover back in 2010 showing that the effects were short lived. This shows that the banks efficiency was impacted by the financial crisis as the ability of converting the inputs into outputs was effected during the time period. The year on year impact has been showing positive movement. This movement trend of the scores shows that the impact of the financial crisis was as a result of the international spillover and not due to any inherent linkages to the global financial sector as the impact would have been more long lived in that scenario, even though it's a good sign as it shows that we remain insulated from any long term effects, but there is still exposure to spillover effects which requires mitigation. It is to be noted that the mean scores provided in all of the following tables are the geometric means.

TABLE I: DESCRIPTIVE STATISTICS (MILLIONS OF RUPEES)

\begin{tabular}{cccc}
\hline Ordinary Profit & Net Profit & Market Value & Debt to Asset Ratio \\
\hline $3,950,944$ & $2,810,190$ & $35,791,112$ & 0.89 \\
$1,408,823$ & $1,012,843$ & $14,201,594$ & 0.92 \\
$-16,832,906$ & $-10,112,114$ & 12,226 & 0.50 \\
$28,060,501$ & $19,033,773$ & $251,279,386$ & 0.98 \\
$8,755,674$ & $6,043,559$ & $51,069,630$ & 0.08 \\
\hline
\end{tabular}

Table III presents the results of the technological change component for all banks during the study period. The technological efficiency is the efficiency of a firm to produce a given amount of output using a given amount of input. This means that if a firm is unable to convert efficiently its inputs to outputs using a given level of inputs then it is said to be technologically inefficient. In our scenario the results indicate that the mean scores were at the lowest during 2008 indicating that in the year of the crisis the banks were unable to fully utilize their potential of efficiently converting inputs to outputs which is attributed to the effect of global financial crisis. This further implies a reduction of the inputs available to the banks. This is evident from the credit shortages during the year, with liquidity drying up in the system and overnight lending rates rising to as high as 40 percent. In this part of the analysis it is again seen that the mean scores rise back up to pre-crisis levels after a year proving once more that the impact was due to international spillover and not internally generated. The shortage in liquidity can be attributed to the herding behavior by the liquidity providers who become less willing to take on risks during a crisis situation in the global markets. Therefore it can be concluded from these results that the impact in the scores is due to the financial crisis.
TABLE II: TECHNICAL EFFICIENCy ChANGE All BANKS

\begin{tabular}{lccccc}
\hline DMU & $\mathbf{2 0 0 7}$ & $\mathbf{2 0 0 8}$ & $\mathbf{2 0 0 9}$ & $\mathbf{2 0 1 0}$ & $\boldsymbol{y} \boldsymbol{y \boldsymbol { y }}$ \\
\hline Allied Bank & 1.023 & 1.093 & 1.058 & 1.161 & 1.083 \\
Askari Bank & 0.893 & 1.068 & 1.068 & 1.348 & 1.083 \\
Atlas Bank & 1.480 & 0.830 & 0.860 & 0.840 & 0.970 \\
Bank Alfalah & 0.981 & 1.012 & 0.976 & 1.152 & 1.028 \\
Bank Al Habib & 1.000 & 1.310 & 1.116 & 1.315 & 1.177 \\
Bank Islami & 1.513 & 2.053 & 0.649 & 1.370 & 1.289 \\
Bank of Khyber & 0.991 & 1.119 & 0.907 & 1.512 & 1.110 \\
Bank of Punjab & 1.135 & 0.709 & 0.866 & 1.101 & 0.936 \\
Faysal Bank & 0.985 & 0.903 & 1.121 & 1.610 & 1.126 \\
Habib Bank Limited & 0.812 & 1.203 & 1.024 & 1.000 & 1.000 \\
Habib Metropolitan Bank & 0.957 & 1.227 & 0.972 & 1.113 & 1.062 \\
Muslim Commercial Bank & 1.276 & 1.000 & 1.000 & 1.000 & 1.063 \\
Meezan Bank & 1.152 & 1.764 & 0.857 & 1.372 & 1.243 \\
MyBank & 1.154 & 1.786 & 0.398 & 0.667 & 0.860 \\
National Bank of Pakistan & 1.000 & 1.000 & 1.000 & 0.285 & 0.731 \\
NIB Bank & 3.780 & 1.044 & 0.896 & 0.734 & 1.269 \\
SAMBA Bank & 3.904 & 0.783 & 0.499 & 1.178 & 1.158
\end{tabular}




\begin{tabular}{llllll} 
Silkbank & 0.715 & 1.215 & 0.861 & 1.214 & 0.976 \\
Soneri Bank & 0.894 & 1.010 & 1.003 & 1.249 & 1.032 \\
United Bank & 1.071 & 1.112 & 1.036 & 1.025 & 1.060 \\
Mean & $\mathbf{1 . 1 8 5}$ & $\mathbf{1 . 1 2 1}$ & $\mathbf{0 . 8 8 2}$ & $\mathbf{1 . 0 5 8}$ & $\mathbf{1 . 0 5 4}$ \\
\hline
\end{tabular}

TABLE III: TECHNOLOGICAL EFFICIENCY CHANGE ALL BANKS

\begin{tabular}{lccccc}
\hline DMU & $\mathbf{2 0 0 7}$ & $\mathbf{2 0 0 8}$ & $\mathbf{2 0 0 9}$ & $\mathbf{2 0 1 0}$ & yoy \\
\hline Allied Bank & 1.228 & 0.696 & 1.282 & 0.987 & 1.020 \\
Askari Bank & 1.228 & 0.792 & 1.155 & 0.908 & 1.005 \\
Atlas Bank & 1.177 & 0.607 & 1.165 & 0.908 & 0.932 \\
Bank Alfalah & 1.228 & 0.902 & 1.155 & 0.908 & 1.038 \\
Bank Al Habib & 1.228 & 0.699 & 1.299 & 0.913 & 1.005 \\
Bank Islami & 1.195 & 0.426 & 1.527 & 0.917 & 0.919 \\
Bank of Khyber & 1.228 & 0.656 & 1.290 & 0.908 & 0.986 \\
Bank of Punjab & 1.228 & 0.775 & 1.156 & 0.908 & 1.001 \\
Faysal Bank & 1.228 & 0.655 & 1.170 & 0.908 & 0.962 \\
Habib Bank Limited & 1.179 & 0.604 & 1.427 & 1.088 & 1.025 \\
Habib Metropolitan Bank & 1.228 & 0.651 & 1.357 & 0.957 & 1.009 \\
Muslim Commercial Bank & 1.247 & 0.498 & 1.434 & 1.116 & 0.999 \\
Meezan Bank & 1.228 & 0.577 & 1.434 & 0.908 & 0.980 \\
MyBank & 1.207 & 0.471 & 1.432 & 0.908 & 0.927 \\
National Bank of Pakistan & 1.158 & 0.654 & 1.170 & 0.986 & 0.967 \\
NIB Bank & 1.215 & 0.605 & 1.358 & 0.922 & 0.979 \\
SAMBA Bank & 1.277 & 0.354 & 1.659 & 0.981 & 0.926 \\
Silkbank & 1.228 & 0.614 & 1.282 & 0.927 & 0.973 \\
Soneri Bank & 1.228 & 0.675 & 1.170 & 0.908 & 0.969 \\
United Bank & 1.219 & 0.636 & 1.252 & 1.042 & 1.003 \\
Mean & $\mathbf{1 . 2 1 9}$ & $\mathbf{0 . 6 1 5}$ & $\mathbf{1 . 3 0 1}$ & $\mathbf{0 . 9 4 9}$ & $\mathbf{0 . 9 8 1}$ \\
\hline & & & & & \\
\hline
\end{tabular}

Table IV shows the results for the pure technical efficiency change, which is the relative ability of the firm to convert inputs into outputs. The results indicate that there is decrease in 2008 and 2009 compared to 2007 showing that the conversion ability is impacted. The scores recover in 2010 showing that the impact was short lived, meaning it was not attributable to the internal systems dynamics but to external stimuli, which is the financial crisis. So far we have seen a consistent trend across the technological, technical and pure technical efficiencies. All of which point towards impact of a external stimuli on the banking system. This argument of external shock is further supported by the normalization of the results in the following year, and a consistent year on year results. Further we will be looking at the scale efficiency and total factor productivity which further support our hypothesis that global financial crisis did indeed impact the banking sector of Pakistan.

Table V shows the results of the scale efficiency scores. The results indicate that the DMU's have performed consistently with respect to their scale for the periods under consideration. Units are considered as scale efficient when there size of operations is optimal and modifications to the size may make the unit less efficient. This shows that the Pakistani banking sector is operating on optimal size during the analysis period and any impacts on performance efficiency is not as a result of size of operations of the banking sector. The results support the argument for external shocks even more as if the scale efficiency component was weak across various time periods then we could have attributed the poor results for the years above to scale inefficiencies of the banking sector. Since the results presented in table 5 prove that the scale efficiency of the banking sector is not the source of the poor results and has been relatively spared from the trends exhibited in the other measures of efficiency, hence it can be assumed that the impact on the efficiencies calculated prior is due to an external stimuli impacting the banking system, which is the global financial crisis.

TABLE IV: PURE TECHNICAL EFFICIENCY CHANGE ALL BANKS

\begin{tabular}{|c|c|c|c|c|c|}
\hline$D M U$ & 2007 & 2008 & 2009 & 2010 & yoy \\
\hline Allied Bank & 1.058 & 1.068 & 1.049 & 1.113 & 1.072 \\
\hline Askari Bank & 0.914 & 1.055 & 1.068 & 1.317 & 1.079 \\
\hline Atlas Bank & 2.508 & 0.445 & 0.910 & 0.891 & 0.975 \\
\hline Bank Alfalah & 0.994 & 0.989 & 0.966 & 1.126 & 1.017 \\
\hline Bank Al Habib & 1.023 & 1.254 & 1.139 & 1.285 & 1.171 \\
\hline Bank Islami & 0.096 & 1.494 & 0.274 & 1.338 & 0.479 \\
\hline Bank of Khyber & 1.349 & 0.868 & 0.927 & 1.775 & 1.178 \\
\hline Bank of Punjab & 1.188 & 0.737 & 0.866 & 1.064 & 0.948 \\
\hline Faysal Bank & 1.020 & 0.912 & 1.133 & 1.573 & 1.135 \\
\hline Habib Bank Limited & 0.869 & 1.151 & 1.000 & 1.000 & 1.000 \\
\hline Habib Metropolitan Bank & 0.969 & 1.191 & 0.968 & 1.087 & 1.050 \\
\hline Muslim Commercial Bank & 1.272 & 1.000 & 1.000 & 1.000 & 1.062 \\
\hline Meezan Bank & 1.205 & 1.726 & 0.864 & 1.327 & 1.243 \\
\hline MyBank & 1.041 & 1.925 & 0.387 & 2.079 & 2.099 \\
\hline National Bank of Pakistan & 1.000 & 1.000 & 1.000 & 0.309 & 0.745 \\
\hline NIB Bank & 5.380 & 1.100 & 0.875 & 0.490 & 1.262 \\
\hline SAMBA Bank & 3.610 & 1.000 & 1.000 & 0.075 & 1.288 \\
\hline Silkbank & 0.755 & 1.115 & 0.927 & 1.126 & 0.968 \\
\hline Soneri Bank & 0.905 & 0.986 & 1.015 & 1.207 & 1.023 \\
\hline United Bank & 1.082 & 1.083 & 1.010 & 0.998 & 1.043 \\
\hline Mean & 1.241 & 1.060 & 0.879 & 1.074 & 1.056 \\
\hline
\end{tabular}

TABLE V: SCALE EFFICIENCY ALL BANKS

\begin{tabular}{lccccc}
\hline DMU & $\mathbf{2 0 0 7}$ & $\mathbf{2 0 0 8}$ & $\mathbf{2 0 0 9}$ & $\mathbf{2 0 1 0}$ & $\boldsymbol{y o y}$ \\
\hline Allied Bank & 0.967 & 1.024 & 1.009 & 1.043 & 1.010 \\
Askari Bank & 0.977 & 1.013 & 1.000 & 1.024 & 1.003 \\
Atlas Bank & 0.590 & 1.865 & 0.946 & 0.942 & 0.995 \\
Bank Alfalah & 0.987 & 1.024 & 1.011 & 1.024 & 1.011 \\
Bank Al Habib & 0.977 & 1.044 & 0.980 & 1.024 & 1.006 \\
Bank Islami & 1.799 & 1.374 & 2.367 & 1.024 & 2.693 \\
Bank of Khyber & 0.734 & 1.290 & 0.978 & 0.852 & 0.943 \\
Bank of Punjab & 0.956 & 0.961 & 1.000 & 1.034 & 0.987 \\
Faysal Bank & 0.966 & 0.990 & 0.989 & 1.023 & 0.992 \\
Habib Bank Limited & 0.935 & 1.045 & 1.024 & 1.000 & 1.000
\end{tabular}




\begin{tabular}{lccccc} 
Habib Metropolitan Bank & 0.988 & 1.030 & 1.004 & 1.024 & 1.011 \\
Muslim Commercial Bank & 1.003 & 1.000 & 1.000 & 1.000 & 1.001 \\
Meezan Bank & 0.956 & 1.022 & 0.991 & 1.034 & 1.000 \\
MyBank & 1.109 & 0.928 & 1.029 & 0.027 & 0.410 \\
National Bank of Pakistan & 1.000 & 1.000 & 1.000 & 0.925 & 0.981 \\
NIB Bank & 0.703 & 0.950 & 1.024 & 1.498 & 1.006 \\
SAMBA Bank & 0.107 & 0.783 & 0.499 & 1.680 & 0.899 \\
Silkbank & 0.946 & 1.090 & 0.929 & 1.079 & 1.009 \\
Soneri Bank & 0.988 & 1.024 & 0.988 & 1.034 & 1.009 \\
United Bank & 0.989 & 1.027 & 1.025 & 1.027 & 1.017 \\
Mean & $\mathbf{0 . 9 5 4}$ & $\mathbf{1 . 0 5 7}$ & $\mathbf{1 . 0 0 4}$ & $\mathbf{0 . 9 8 1}$ & $\mathbf{0 . 9 9 8}$ \\
\hline
\end{tabular}

TABLE VI: TOTAL FACTOR PRODUCTIVITY ALL BANKS

\begin{tabular}{|c|c|c|c|c|c|}
\hline$D M U$ & 2007 & 2008 & 2009 & 2010 & yoy \\
\hline Allied Bank & 1.257 & 0.761 & 1.357 & 1.146 & 1.104 \\
\hline Askari Bank & 1.097 & 0.846 & 1.233 & 1.225 & 1.088 \\
\hline Atlas Bank & 1.742 & 0.504 & 1.002 & 0.763 & 0.905 \\
\hline Bank Alfalah & 1.206 & 0.913 & 1.127 & 1.046 & 1.067 \\
\hline Bank Al Habib & 1.228 & 0.915 & 1.450 & 1.202 & 1.183 \\
\hline Bank Islami & 1.807 & 0.875 & 0.992 & 1.256 & 1.185 \\
\hline Bank of Khyber & 1.217 & 0.734 & 1.170 & 1.373 & 1.095 \\
\hline Bank of Punjab & 1.394 & 0.549 & 1.001 & 1.000 & 0.936 \\
\hline Faysal Bank & 1.210 & 0.592 & 1.311 & 1.462 & 1.082 \\
\hline Habib Bank Limited & 0.957 & 0.727 & 1.461 & 1.088 & 1.025 \\
\hline Habib Metropolitan Bank & 1.175 & 0.799 & 1.319 & 1.065 & 1.072 \\
\hline Muslim Commercial Bank & 1.591 & 0.498 & 1.434 & 1.116 & 1.061 \\
\hline Meezan Bank & 1.415 & 1.018 & 1.228 & 1.246 & 1.219 \\
\hline MyBank & 1.393 & 0.842 & 0.569 & 0.606 & 0.798 \\
\hline National Bank of Pakistan & 1.158 & 0.654 & 1.170 & 0.282 & 0.707 \\
\hline NIB Bank & 4.593 & 0.631 & 1.216 & 0.676 & 1.243 \\
\hline SAMBA Bank & 4.985 & 0.278 & 0.828 & 1.156 & 1.073 \\
\hline Silkbank & 0.878 & 0.747 & 1.104 & 1.126 & 0.950 \\
\hline Soneri Bank & 1.099 & 0.681 & 1.174 & 1.134 & 0.999 \\
\hline United Bank & 1.305 & 0.707 & 1.297 & 1.067 & 1.063 \\
\hline Mean & 1.444 & 0.689 & 1.149 & 1.000 & 1.034 \\
\hline
\end{tabular}

Table VI talks about the Total Factor Productivity (TFP) of the banking sector. Total factor productivity is the portion of output not explained by the quantity of inputs used in the production process. Hence, the level of total factor productivity is determined by how intensely and efficiently the inputs are utilized in production (Comin 2006). The results indicate almost all the DMU's underperformed during 2008 as their TFP scores are below 1, with the exception of Meezan bank which is the outlier with an efficiency score above 1 . This finding is in line with previous works indicating that Islamic banks performed superior during the financial crisis then the conventional banks due to their asset composition, investment portfolios and prohibition of RIBA based activities. The results are a clear indication that the
Pakistani banking sector was indeed impacted by the 2008 global financial crisis that impacted the global financial markets. This is an important finding and has implications for policy makers as it shows the vulnerability of our local sector to shocks in the global economy and requires measures to be taken to insulate against any such shocks in the future.

All the results indicate that the banking sector is efficient in terms of the utilization of the size of operations, but the crisis caused major problems to the technical and technological efficiency and total factor productivity, but as the results improve back by 2010 this indicates that the shock was not intrinsic and was only temporary, which is attributable to the financial crisis. The results prove the first hypothesis as the technical, technical and pure efficiency values were impacted as a result of the financial crisis. The second hypothesis that predicted that the scale efficiency would not be impacted as the crisis is due to international spillover and not originated in Pakistan is also proven to be correct. The third hypothesis stated that the total factor productivity would be impacted but would return to pre-crisis level soon after the initial impact of the crisis. This is also proven by the results as the values of total factor productivity reduced substantially during the crisis originating time period but turned back to pre-crisis levels soon after, once again proving that the impact on the Pakistani banking sector was temporary and not intrinsically caused, but was due to international spillover caused by the global financial crisis.

\section{CONCLUSION}

Financial markets can no longer operate in isolation; the fact is that the events in the global markets find their way to the domestic markets in one way of the other. The study proves it through the use of non-parametric measures using DEA analysis using Malmquist index. One of the major issues while conducting non-parametric studies using DEA is that of variable selection. This study is the first of its kind, to the authors knowledge, that uses variables found using advanced statistical techniques and use them in the analysis, adding value to the results of this study over those that employ variables otherwise selected. The results indicate that the Pakistani banking sector was indeed affected by the global financial crisis as the total factor productivity of the banking sector was significantly impacted, while the scale efficiency was not impacted showing, that the effects of the crisis on Pakistan were spill over and not due to any strong financial linkages as then the impact would have been visible for a longer period of time hence both the hypothesis of the study were proven to be true. Also it is seen that the adverse effects of the spill over were least felt by the Islamic banks in the country which is in line with previous empirical research on the performance measure of the Islamic banking sector during the crisis. Further work needs to be done to identify the channel of transmission of the shock to be able to better handle any such event in the future.

\section{REFERENCES}

[1] M. D. Fethi and F. Pasiouras, "Assessing bank efficiency and performance with operational research and artificial intelligence 
techniques: A survey," European Journal of Operational Research, vol. 204, no. 2, pp. 189-198, Jul. 2010.

[2] I. A. Danesh, "An investigation of islamic banks performance: A comparison with conventional banks," Masters Thesis, School of Management, Cranfield University, UK, 2007.

[3] H. Morita, N. K. Avkiran, "Selecting inputs and outputs in data envelopment analysis by designing statistical experiments," Special Issue of Operations Research for Performance Evaluation, Journal of the Operations Research Society of Japan, vol. 52 no. 2, pp. 163-173, June 2009.

[4] S. Javaid, J. Anwer, K. Zaman, and A. Gaffor, "Determinants of bank profitability in Pakistan: Internal factor analysis," Mediterranean Journal of Social Sciences, vol. 2 no. 1, pp. 59-78, 2011.

[5] A. Nazeer, S. Khuram, I. Zahra, and L. Hua, "Impact of financial crisis on an economy: Pakistan as a case," American Journal of Service Science and Management, vol. 2 no. 2, pp. 14-17, 2015.

[6] Nazir, M.S., Safdar, R. and Akram, M.I., "Impact of global financial crisis on banks' financial performance in Pakistan," American Journal of Scientific Research, issue 78, pp. 101-110, Oct. 2012.

[7] L. A. Phulpoto, A. B. Shah, and F. M. Shaikh, "Global financial crises and its impact on banking sector in Pakistan," Journal of Asian Business Strategy, vol. 2, no. 6, p. 142, Jun 2012.

[8] M. Oberholzer, G. V. D. Westhuizen, and S. V. Rooyen, "The influence of banks' internal performance on market performance: A non-parametric approach," Southern African Business Review, vol. 14, no. 2, pp. 65-88, 2010

[9] M. Usman, Z. Wang, F. Mahmood and H. Shahid, "Scale efficiency in banking sector of Pakistan," International Journal of Business and Management, vol.5, no. 4, p. 104, Apr. 2010.

[10] A. Haque and A. Tariq, "Efficiency of banks in Pakistan: A non parametric approach," Business and Economic Research, vol. 2, no. 1, Jan. 2012.

[11] P. O. Eriki and O. Osagie, "Performance efficiency of selected quoted commercial banks in Nigeria: A DEA approach," International
Journal of Economics, Commerce and Management, vol. 2, no. 9, 2014.

[12] R. Madhanagopal and R. Chandrasekaran, "Selecting appropriate Variables for DEA using genetic algorithm (GA) search procedure," International Journal of Data Envelopment Analysis and Operations Research, vol.1, no. 2, pp. 28-33, Jan. 2014.

[13] J. T. Pastor, J. L. Ruiz, and I. Sirvent, "A statistical test for nested radial DEA models," Operations Research, vol. 50, no. 4, pp. 728-735, Aug. 2002.

[14] A. de la Fuente and A. Estache, "Infrastructure productivity and growth: A quick survey," Washington DC: WBIGF (mimeo), 2004.

[15] R. Färe and S. Grosskopf, "Estimation of returns to scale using data envelopment analysis: A comment," European Journal of Operational Research, vol. 79, no. 2, pp. 379-382, Dec. 1994.

[16] R. Färe and D. Njinkeu, "Computing returns to scale under alternative models," Economics Letters, vol. 30 no. 1, pp. 55-59, Jan. 1989

[17] T. J. Coelli, "Centre for efficiency and productivity analysis (CEPA) working papers," Department of Econometrics, University of New England, Armidale, Australia, 1996.

[18] R. Färe, S. Grosskopf, B. Lindgren, and P. Roos, "Productivity developments in Swedish hospitals: A Malmquist output index approach," Data Envelopment Analysis: Theory, Methodology, and Applications, Springer Netherlands, pp. 253-272, 1994.

[19] C. Diego, "Total factor productivity. In economic growth," Palgrave Macmillan, UK, pp. 260-263, 2010.

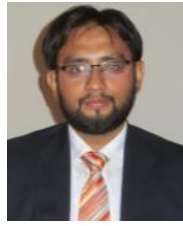

Asim Rehman got his MBA in 2010 with majors in finance and investment from National University of Science and Technology, Islamabad, Pakistan. He is currently pursuing his $\mathrm{Ph} . \mathrm{D}$. from the same university

He has experience working in management consulting and the financial sector. 